\title{
Older people and COVID-19 updates by medical postgraduate colleges in UK and Ireland
}

\author{
Amy Lynch ${ }^{1} \cdot$ Desmond O'Neill $^{1}$ (1) \\ Received: 11 June 2020 / Accepted: 21 June 2020 / Published online: 10 July 2020 \\ (c) European Geriatric Medicine Society 2020
}

Keywords COVID-19 · Ageing · Continuous professional development · Ageism

\section{Are older people adequately profiled in COVID-19 training?}

Older people represent the key demographic affected by mortality and morbidity of the COVID-19 pandemic-94\% of deaths in Europe have been in people over the age of 60 [1]—but there are concerns that this vulnerability has not been accorded due prominence by international health bodies such as the WHO [2]. This may reflect a wider failure to recognize the needs of this group by the profession in general. As there have been significant efforts to provide updates on managing COVID-19 by many medical postgraduate training bodies, we assessed the relative prominence and timeliness of focused presentations on older people by four postgraduate medical colleges in the UK and Ireland: the Royal Colleges of Physicians of Ireland, London and Edinburgh, and the Royal College of Physicians and Surgeons of Glasgow.

We analyzed schedules and content accessible on their websites of clinical update teaching presentations and videocasts to calculate the proportion of topics specifically addressing older people, as well as their scheduling. We included talks given from 12/02/2020-07/05/2020, a 14 -week period spanning the beginning and evolution of the pandemic.

Of 80 talks given by the 4 colleges, seven (9\%) directly related to older people. In terms of scheduling, a specific focus on older people appeared on the seventh week of weekly clinical updates in one college, and on the second week for another on issues relating to anticipatory

Desmond O’Neill

doneill@tcd.ie

1 Centre for Ageing, Neuroscience and the Humanities, Trinity College Dublin, Trinity Centre for Health Sciences, Tallaght University Hospital, Dublin 2 D24 NR0A, Ireland care planning including older people. No clear dates were attached to talks given by the third college, with one session addressing care needs of older patients. No presentation specifically relating to older people featured on the COVID-19 presentations of the fourth college.

The impact, varied clinical presentations [3], management strategies, and approaches to the complexities of the interface between care homes and hospitals [4] for older people requires significant expertise and skills which are critical in the management of those most gravely affected by the pandemic. Adequate and timely education for physicians to address these issues in updates by postgraduate educational bodies is warranted and does not appear to be proportionate in timing or content to the burden of morbidity and mortality of older people from COVID-19 in the UK and Ireland. A learning outcome of this pandemic should be to encourage stronger joint working with geriatric medicine and a closer proportionality between the populations most affected in the content and scheduling of medical postgraduate educational initiatives for emergent crises, disaster and pandemic planning [5].

\section{Compliance with ethical Standards}

Conflict of interest The authors declare no conflict of interest.

Ethical approval This article does not contain any studies with human participants performed by any of the authors.

\section{References}

1. Regional Office for Europe WHO (2020) COVID-19 weekly surveillance report: data for the week of 4-10 May 2020 (Epi week 19). Regional Office for Europe WHO, Geneva 
2. Lloyd-Sherlock PG, Kalache A, McKee M, Derbyshire J, Geffen L, Casas FG (2020) WHO must prioritise the needs of older people in its response to the covid-19 pandemic. BMJ 368:m1164

3. D'Adamo H, Yoshikawa T, Ouslander JG (2020) Coronavirus disease 2019 in geriatrics and long-term care: the ABCDs of COVID-19. J Am Geriatr Soc 68(5):912-917

4. Fallon A, Dukelow T, Kennelly SP, O'Neill D. COVID-19 in Nursing Homes. QJM : monthly journal of the Association of Physicians. 2020.
5. Johnson HL, Ling CG, McBee EC (2015) Multi-disciplinary care for the elderly in disasters: an integrative review. Prehosp Disaster Med 30(1):72-79

Publisher's Note Springer Nature remains neutral with regard to jurisdictional claims in published maps and institutional affiliations. 